\title{
A changing profile of infective endocarditis at a tertiary hospital in China: a retrospective study from 2001 to 2018
}

\author{
Zuning Ren, Xichao Mo, Hongjie Chen and Jie Peng*
}

\begin{abstract}
Background: Infective endocarditis (IE) is a lethal disease which has been changing significantly over the past decades; however, information about IE in China remains scarce. This study surveyed the changes in clinical characteristics of IE at a tertiary hospital in south China over a period of nearly 18 years.

Methods: Medical records with IE patients consecutively hospitalized between June 2001 and June 2018 were selected from the electronic medical records system in Nanfang Hospital of Southern Medical University. Data were divided by admission time into two groups equally: early-period group, June 2001 to December 2009 and laterperiod group, January 2010 to July 2018.

Results: A Total of 313 IE patients were included in our study. Compared with the early-period group, patients in the later-period group included fewer intravenous drug users (IVDUs), older age at onset, reduced development of pulmonary embolism, less renal dysfunction, decreased proportion of Staphylococcus aureus infection and fewer vegetations observed in the right heart by echocardiography. The later-period group also showed a higher proportion of ischemic strokes and higher proportion of positive microbiological findings compared with the earlyperiod group. The in-hospital mortality remained about the same between the two periods and the multivariate analysis identified intravenous drug addicted, prosthetic valve endocarditis, hemorrhagic stroke, acute congestive heart failure, renal insufficiency, left-sided endocarditis, early surgical as independent predictors of in-hospital mortality.

Conclusions: Our study demonstrated a dramatic change in the profile of IE over a period of 18 years at a tertiary hospital in south China and presented several independent predictors of in-hospital mortality. The geographic variations observed in our study will be of important value to profile the clinical feature of China and offer the reference for clinical decisions in our region.
\end{abstract}

Keywords: Infective endocarditis, Clinical characteristics, Risk factors, Mortality, Retrospective study, Independent predictors

\section{Background}

Infective endocarditis is a lethal disease caused by various pathogens such as bacteria, fungi, and rickettsia that directly invade the cardiac valves or mural endocardium [1]. The profile of IE has been changing significantly over the past decades [2]. Overall, IE related to rheumatic diseases has dramatically decreased in developed countries, being gradually replaced by IE associated with

\footnotetext{
* Correspondence: pjie138@163.com

Department of Infectious Diseases, Nanfang Hospital, Southern Medical University, Guangzhou 510515, China
}

congenital heart disease, degenerative heart valve disease, prosthetic valves and cardiac implantable electronic devices [3]. Staphylococci, which are most often related to healthcare and invasive procedures, have overtaken streptococci as the most common pathogen of IE [4]. The average age of patients has also been increasing [5]. In contrast, rheumatic disease remains a key predisposing factor in developing countries, and streptococci are still the most common cause of IE. In countries with reduced IVDU, right heart IE has also decreased; but in some regions such as eastern Europe, IVDU remains a 
problem and right-sided IE continues to occur [6]. Many developed countries have a wealth of prospective or retrospective studies for IE [7-9]. However, there have been few studies of IE in China compared to other countries [10]. To better profile the features of IE and the changes in clinical characteristics at Nanfang Hospital, a tertiary hospital in southern China, and find out the independent predictors of in-hospital mortality, we collected and analyzed the data from consecutive 313 cases of IE over a period of 18 year.

\section{Methods}

\section{Diagnostic criteria}

The definition of cases was based on the European Society of Cardiology (ESC) algorithm for diagnosis of infective endocarditis (2015 edition) [11], which mainly includes the pathological diagnostic criteria and the modified Duke criteria.

Pathological examination served as the gold standard for diagnosing IE, which must meet at least one of the following criteria: microorganisms demonstrated by culture or on histological examination of a vegetation, a vegetation that has embolized, or an intracardiac abscess specimen or the presence of pathological lesions, vegetation or intracardiac abscesses by histological examination showing active endocarditis.

The modified Duke criteria (adapted from Li et al. [12]) were used for clinical diagnosis with cases classified as either definite or suspected. For a diagnosis of definite IE, the patient must meet two major criteria, or one major criterion and three minor criteria, or five minor criteria. For a diagnosis of suspected IE, the patient must meet one major criterion and one minor criterion or three minor criteria. Major criteria include: (1) blood cultures positive for typical microorganisms consistent with IE from two separate blood cultures, microorganisms consistent with IE from persistently positive blood cultures; (2) imaging positive for IE by transthoracic echocardiogram; and (3) definite paravalvular lesions by cardiac CT. Minor criteria include: (1) predisposing heart condition or injection drug use; (2) fever of $>38^{\circ} \mathrm{C}$; (3) vascular phenomena including those detected by imaging only, major arterial emboli, septic pulmonary infarcts, infectious mycotic aneurysm, intracranial hemorrhage, conjunctival hemorrhages, and Janeway's lesions; (4) immunological phenomena, glomerulonephritis, Osler's nodes, Roth's spots, or rheumatoid factor; (5) microbiological evidence, positive blood culture, but does not meet a major criterion as noted above or serological evidence of active infection with organisms consistent with IE. To exclude misdiagnosed cases as sepsis, non-infective endocarditis and rheumatic myocarditis, suspected patients should either show intracardiac vegetations by echocardiography with an evidence of bacterial infection, or meet the pathological diagnostic criteria.
Health care-associated IE was considered likely if any of the following had occurred: the patient had received intravenous therapy at home, received wound care or specialized nursing care through a health care agency, family, or friends, self-administered intravenous medical therapy in the past 30days, was examined at a hospital or hemodialysis clinic or received intravenous chemotherapy in the past 30 days, was hospitalized in an acute care hospital for two or more days in the previous 90 days before the infection, or resided in a nursing home or long-term care facility [13].

Early surgery was defined as surgery within 20 days after diagnosis of IE [14]. On the contrary, late surgery was defined as surgical intervention beyond 20 days after diagnosis.

In-hospital mortality was defined as death from any cause during hospitalization.

\section{Study sample}

Nanfang Hospital of Southern Medical University is a large tertiary teaching comprehensive hospital at Guangdong province in southern China with in-patient quantity up to 119,000 statistically in 2018 , where surgery quantity in cardiothoracic surgery surpasses 1000 per year. We consecutively collected 313 inpatients diagnosed with IE through the electronic medical records system of Nanfang Hospital between June 2001 and June 2018. They were divided into two groups according to their time of admission: early-period group, from June 2001 to December 2009, and later-period group, from January 2010 to July 2018.

This clinical study was a retrospective and descriptive study consistent with the principles of the Helsinki declaration.

Data included demographic information, predisposing factors, clinical manifestations, laboratory tests including blood work and biochemical measurements, echocardiography results, causative microorganisms, pathologic findings and therapeutic outcomes. The outcomes included improvement at discharge of clinical symptoms, normal laboratory indicators, negative blood cultures and echocardiograms and worsening at discharge with abandonment of treatment because of poor efficacy or death.

\section{Statistical method}

All analyses were performed using SPSS version 25.0.0. Continuous variables fitting a normal distribution were expressed as mean \pm standard deviation. Categorical variables were expressed as frequency and percentage. Univariate comparisons were evaluated with the use of the independent sample $t$ test for continuous variables, and Chi-squared tests or Fisher's exact test for categorical variables, if appropriate. Variables with theoretical clinical 
importance and those that achieved a $P$ value of $<0.10$ in the univariate analysis were included in the binary logistic regression analysis. A forward conditional method was used to select the most useful predictors of the in-hospital mortality. A value of $P<0.05$ was considered significant.

\section{Results}

\section{Basic information}

A total of 313 IE patients were consecutively collected in this study, with 97 patients enrolled in the early-period group and 216 patients in the later-period group. Table 1 shows the basic information of the 313 patients. The laterperiod group was on average older $(44.9 \pm 15.4 \mathrm{yrs}$. vs $36.5 \pm 15.2$ yrs., $P<0.001,4.692-12.064$ ), mainly due to more patients aged $41-60$ years old $(43.1 \%$ vs. $23.7 \%$, $\mathrm{OR}=2.433$, CI: 1.418-4.174), and fewer patients aged 21$40(35.2 \%$ vs. $56.7 \%, \mathrm{OR}=0.415$, CI: 0.254-0.676). Each group had a similar male-female ratio, approximately 2.6:1 (72.2\%). The top five departments that IE patients were initially admitted were cardiology (28.4\%), cardiothoracic surgery (25.6\%), infectious disease (15.0\%), respiratory (7.7\%), and nephrology (5.1\%). The proportion of patients in the respiratory department declined in the later-period group ( $4.6 \%$ vs $14.4 \%$, OR $=0.288$, CI: $0.123-0.674)$. Regarding the factors predisposing to IE, 21 cases (6.7\%) were considered as healthcare-associated IE. Basic heart diseases were the dominant predisposing factors (45.4\%), including rheumatic heart disease (19.2\%), congenital heart disease $(16.6 \%)$ and degenerative heart valve disease (7.7\%). IVDUs in the later-period group sharply decreased compared to the early-period group $(12.0 \%$ vs $25.8 \%$, OR = 0.394, CI: $0.214-0.727)$. The proportion of diabetic patients was higher in the later-period group, but without statistical significance (10.6\% vs. $5.2 \%)$.

\section{Manifestations and complications}

Table 2 details the manifestations and complications of the 313 IE patients in this study. Our results showed that two groups had similar clinical features, including fever, heart murmurs, hypoproteinemia, anemia, chest pain,

Table 1 Patient characteristics

\begin{tabular}{|c|c|c|c|c|c|c|c|}
\hline \multirow[t]{2}{*}{ Variable } & \multirow{2}{*}{$\begin{array}{l}\text { Total } \\
N=313\end{array}$} & \multirow{2}{*}{$\begin{array}{l}\text { Early-period Group } \\
N=97\end{array}$} & \multirow{2}{*}{$\begin{array}{l}\text { Later-period Group } \\
N=216\end{array}$} & \multirow[t]{2}{*}{ OR } & \multicolumn{2}{|l|}{$95 \% \mathrm{Cl}$} & \multirow[t]{2}{*}{$P$} \\
\hline & & & & & Lower & Upper & \\
\hline Age (year) & $42.3 \pm 15.8$ & $36.5 \pm 15.2$ & $44.9 \pm 15.4$ & & -4.692 & -12.064 & $<0.001^{*}$ \\
\hline$\leq 20$ & $18(5.8)$ & $9(9.3)$ & ik9 (4.2) & 0.425 & 0.163 & 1.107 & 0.072 \\
\hline $21-40$ & $131(41.9)$ & $55(56.7)$ & $76(35.2)$ & 0.415 & 0.254 & 0.676 & $<0.001$ \\
\hline $41-60$ & $116(37.1)$ & $23(23.7)$ & $93(43.1)$ & 2.433 & 1.418 & 4.174 & 0.001 \\
\hline$\geq 61$ & $48(15.3)$ & $10(10.3)$ & $38(17.6)$ & 1.857 & 0.884 & 3.902 & 0.098 \\
\hline Male & $226(72.2)$ & $70(72.2$ & $156(72.2)$ & 1.003 & 0.588 & 1.712 & 0.992 \\
\hline \multicolumn{8}{|l|}{ Admission departments } \\
\hline Department of Cardiology & $89(28.4)$ & $26(26.8)$ & $63(29.2)$ & 1.124 & 0.657 & 1.923 & 0.668 \\
\hline Department of Cardiothoracic Surgery & $80(25.6)$ & 19 (19.6) & $61(28.2)$ & 1.616 & 0.902 & 2.892 & 0.105 \\
\hline Department of Infectious Disease & $47(15.0)$ & $10(10.3)$ & $37(17.1)$ & 1.798 & 0.855 & 3.784 & 0.118 \\
\hline Department of Respiratory & $24(7.7)$ & $14(14.4)$ & $10(4.6)$ & 0.288 & 0.123 & 0.674 & 0.003 \\
\hline Department of Nephrology & $16(5.1)$ & $8(8.2)$ & $8(3.7)$ & 0.428 & 0.156 & 1.176 & 0.158 \\
\hline \multicolumn{8}{|l|}{ Predisposing factors } \\
\hline Health care-related & $21(6.7)$ & $3(3.1)$ & $18(8.3)$ & 2.848 & 0.819 & 9.909 & 0.087 \\
\hline Basic heart disease & $142(45.4)$ & $47(48.5)$ & $95(44.0)$ & 0.835 & 0.517 & 1.350 & 0.462 \\
\hline Congenital heart disease & $52(16.6)$ & $20(20.6)$ & $32(14.8)$ & 0.670 & 0.361 & 1.243 & 0.202 \\
\hline Rheumatic heart disease & $60(19.2)$ & $22(22.7)$ & $38(17.6)$ & 0.728 & 0.403 & 1.313 & 0.290 \\
\hline Degenerative heart valve disease & $24(7.7)$ & $4(4.1)$ & $20(9.3)$ & 2.372 & 0.789 & 7.138 & 0.114 \\
\hline Intravenous drug users & $51(16.3)$ & $25(25.8)$ & $26(12.0)$ & 0.394 & 0.214 & 0.727 & 0.002 \\
\hline Prosthetic valve replacement & $11(3.5)$ & $3(3.1)$ & $8(3.7)$ & 1.205 & 0.313 & 4.644 & 0.952 \\
\hline Pacemaker & $3(1.0)$ & $1(1.0)$ & $2(0.9)$ & 1.000 & 0.080 & 10.014 & $0.897+$ \\
\hline Previous IE history & $8(2.6)$ & $2(2.1)$ & $6(2.8)$ & 1.357 & 0.239 & 6.848 & 0.987 \\
\hline Recent skin infection & $10(3.2)$ & $3(3.1)$ & $7(3.2)$ & 1.049 & 0.266 & 4.147 & 0.781 \\
\hline Diabetes & $28(8.9)$ & $5(5.2)$ & $23(10.6)$ & 2.193 & 0.808 & 5.951 & 0.115 \\
\hline
\end{tabular}

Age is presented as mean \pm standard deviation. Other variables are presented as count (\%). $P$ value were estimated by *independent sample $t$ test, Chi-squared tests or FFisher exact tests. One patient could have two or more underlying predisposing factors 
Table 2 Manifestations and complications of 313 patients

\begin{tabular}{|c|c|c|c|c|c|c|c|}
\hline \multirow[t]{2}{*}{ Variable } & \multirow{2}{*}{$\begin{array}{l}\text { Total } \\
N=313\end{array}$} & \multirow{2}{*}{$\begin{array}{l}\text { Early-period Group } \\
N=97\end{array}$} & \multirow{2}{*}{$\begin{array}{l}\text { Later-period Group } \\
N=216\end{array}$} & \multirow[t]{2}{*}{ OR } & \multicolumn{2}{|l|}{$95 \% \mathrm{Cl}$} & \multirow[t]{2}{*}{$P$} \\
\hline & & & & & Lower & Upper & \\
\hline \multicolumn{8}{|l|}{ Manifestations } \\
\hline Fever & $262(83.7)$ & $81(83.5)$ & 181(83.8) & 1.022 & 0.535 & 1.951 & 0.949 \\
\hline Cardiac murmurs & $262(83.7)$ & $87(89.7)$ & 175(81.0) & 0.491 & 0.235 & 1.026 & 0.055 \\
\hline Splenomegaly & $72(23.0)$ & $15(15.5)$ & $57(26.4)$ & 1.960 & 1.046 & 3.673 & 0.034 \\
\hline Chest pain & $38(12.1)$ & $14(14.4)$ & $24(11.1)$ & 0.741 & 0.365 & 1.504 & 0.405 \\
\hline Janeway lesion & $11(3.5)$ & $6(6.2)$ & $5(2.3)$ & 0.359 & 0.107 & 1.208 & 0.165 \\
\hline Osler nodes & $5(1.6)$ & $3(3.1)$ & $2(0.9)$ & 0.293 & 0.048 & 1.781 & 0.354 \\
\hline \multicolumn{8}{|l|}{ Labotory foundings } \\
\hline Leukocytosis or neutrophilia & $199(63.6)$ & $64(66.0)$ & $135(62.5)$ & 0.859 & 0.520 & 1.420 & 0.554 \\
\hline Anemia & $247(78.9)$ & $80(82.5)$ & $167(77.3)$ & 0.724 & 0.392 & 1.336 & 0.301 \\
\hline Hypoproteinemia & $293(93.6)$ & $90(92.8)$ & $203(94.0)$ & 1.215 & 0.469 & 3.146 & 0.689 \\
\hline \multicolumn{8}{|l|}{ Comlications } \\
\hline Heart insufficiency & $182(58.1)$ & $60(61.9)$ & $122(56.5)$ & 0.800 & 0.490 & 1.307 & 0.343 \\
\hline Acute congestive heart failure & $67(21.4)$ & $23(23.7)$ & $44(20.4)$ & 0.823 & 0.464 & 1.460 & 0.505 \\
\hline Embolism & $82(26.2)$ & 19 (19.6) & $63(29.2)$ & 1.690 & 0.946 & 3.022 & 0.075 \\
\hline Ischemic stroke & $69(22.0)$ & $10(10.3)$ & $59(27.3)$ & 3.269 & 1.592 & 6.714 & $<0.001$ \\
\hline Pulmonary embolism & $11(3.5)$ & $7(7.2)$ & $4(1.9)$ & 0.243 & 0.069 & 0.849 & 0.040 \\
\hline Renal infarction & $7(2.2)$ & $3(3.1)$ & $4(1.9)$ & 0.591 & 0.130 & 2.694 & 0.785 \\
\hline Splenic infarction & $20(6.4)$ & $4(4.1)$ & $16(7.4)$ & 1.860 & 0.605 & 5.717 & 0.272 \\
\hline Hemorrhagic stroke & $27(8.6)$ & $7(7.2)$ & $20(9.3)$ & 1.312 & 0.535 & 3.215 & 0.552 \\
\hline Metastatic abscess & $18(5.8)$ & $6(6.2)$ & $12(5.6)$ & 0.897 & 0.326 & 2.463 & 0.832 \\
\hline Pulmonary abscess & $14(4.5)$ & $4(4.1)$ & $10(4.6)$ & 1.129 & 0.345 & 3.692 & 0.924 \\
\hline Cerebral abscess & $7(2.2)$ & $3(3.1)$ & $4(1.9)$ & 0.591 & 0.130 & 2.694 & 0.785 \\
\hline Renal insufficiency & $28(8.9)$ & $15(15.5)$ & $13(6.0)$ & 0.350 & 0.160 & 0.768 & 0.007 \\
\hline No complications & $27(8.6)$ & $9(9.3)$ & $18(8.3)$ & 0.889 & 0.384 & 2.056 & 0.783 \\
\hline
\end{tabular}

Variables are presented as count (\%). $P$ value were estimated by Chi-squared tests. One patient could have two or more manifestations and complications

heart insufficiency, embolism and hemorrhagic stroke despite radiographically visible splenomegaly $(26.4 \%$ vs $15.5 \%, \mathrm{OR}=1.960, \mathrm{CI}: 1.046-3.673)$ and ischemic stroke $(27.3 \%$ vs $10.3 \%$, OR $=3.269$, CI: $1.592-6.714)$, which was more frequently found in later-period group, while pulmonary embolism $(1.9 \%$ vs $7.2 \%$, OR $=0.243$, CI: $0.069-0.849)$ and renal failure $(6.0 \%$ vs $15.5 \%, \mathrm{OR}=$ 0.350 , CI: $0.160-0.768)$ seemed to appear less often in later-period group.

\section{Blood culture}

All 311 IE patients in our study were subjected to blood culture, while blood culture-negative IE (BCNE) patients accounted for $41.8 \%$. The BCNE rate of the later-period group was lower than that of the earlier group $(37.0 \%$ vs $52.6 \%$, OR $=0.529$, CI: $0.325-0.863$ ). The types of microorganism found in the 181 patients with positive blood culture results are summarized in Table 3. Grampositive cocci $(89.0 \%)$ dominated the list, followed by Gram-negative bacilli (6.1\%), other bacterial (3.9\%) and fungi (3.3\%). Staphylococcus aureus and Streptococcus were separately the most frequent microorganism in earlier-period group and later-period group. The presence of Staphylococcus aureus in the later-period group was less common than in the early-period group (20.0\% vs $41.3 \%$, OR $=0.355$, CI: $0.172-0.732$ ). Instead, with the exception of Staphylococcus aureus and streptococcus, other gram-positive cocci, such as Enterococcus $(9.6 \%$ vs $2.2 \%$ ) and Globicatella Sanguis (6.7\% vs $4.3 \%$ ), got a notably increase $(27.4 \%$ vs $13.0 \%$, OR $=2.517$, CI: $0.985-$ $6.429)$ in later-period group.

\section{Echocardiography}

All patients underwent a transthoracic echocardiography (TTE) examination and 274 (87.5\%) showed positive results (Table 4). Only 3 patients of prosthetic valve endocarditis, with negative TTE results, were confirmed by transesophageal echocardiography (TOE). The proportion of negative TTE results was 45.5 and $11.3 \%$ respectively for prosthetic valve endocarditis and native valve 
Table 3 Microorganism found in the 181 patients with positive blood culture results

\begin{tabular}{|c|c|c|c|c|c|c|c|}
\hline \multirow[t]{2}{*}{ Variable } & \multirow{2}{*}{$\begin{array}{l}\text { Total } \\
N=181\end{array}$} & \multirow{2}{*}{$\begin{array}{l}\text { Early-period Group } \\
N=46\end{array}$} & \multirow{2}{*}{$\begin{array}{l}\text { Later-period Group } \\
N=135\end{array}$} & \multirow[t]{2}{*}{ OR } & \multicolumn{2}{|l|}{$95 \% \mathrm{Cl}$} & \multirow[t]{2}{*}{$P$} \\
\hline & & & & & Lower & Upper & \\
\hline Gram-positive coccus & $161(89.0)$ & $40(87.0)$ & $121(89.6)$ & 1.296 & 0.467 & 3.599 & 0.617 \\
\hline Staphylococcus aureus & $46(25.4)$ & $19(41.3)$ & $27(20.0)$ & 0.355 & 0.172 & 0.732 & 0.004 \\
\hline Streptococcus & $76(42.0)$ & $17(37.0)$ & $59(43.7)$ & 1.324 & 0.665 & 2.636 & 0.423 \\
\hline Other & $43(23.8)$ & $6(13.0)$ & $37(27.4)$ & 2.517 & 0.985 & 6.429 & 0.048 \\
\hline Enterococcus & $14(7.7)$ & $1(2.2)$ & $13(9.6)$ & 4.795 & 0.610 & 37.715 & 0.188 \\
\hline Globicatella Sanguis & $11(6.1)$ & $2(4.3)$ & $9(6.7)$ & 1.571 & 0.327 & 7.554 & 0.833 \\
\hline Gram-negative bacilli & $11(6.1)$ & $1(2.2)$ & $10(7.4)$ & 3.600 & 0.448 & 28.922 & 0.355 \\
\hline Other bacterial & $7(3.9)$ & $2(4.3)$ & $5(3.7)$ & 0.846 & 0.158 & 4.518 & 0.805 \\
\hline Fungi & $6(3.3)$ & $3(6.5)$ & $3(2.2)$ & 0.326 & 0.063 & 1.674 & 0.352 \\
\hline
\end{tabular}

Variables are presented as count (\%). P value were estimated by Chi-squared tests. One patient could be isolated two or more kinds of causative microorganisms from blood culture

endocarditis. There were significantly more negative results in the later-period group than in the early-period group $(15.3 \%$ vs $6.2 \%$, OR $=2.735$, CI: $1.106-6.764)$. We observed that 199 (63.6\%) cases were left-sided endocarditis, 60 (19.2\%) cases were right-sided endocarditis, 9 (2.9\%) cases showed vegetations on both sides of cardiac valve, and 6 cases developed vegetations on non-valvular endocardium. The later-period group presented a lower proportion of right-sided endocarditis compared to the early-period group $(16.2 \%$ vs $25.8 \%$, OR $=0.557$, CI: 0.311-0.996), especially for endocarditis on tricuspid valve $(14.8 \%$ vs $24.7 \%$, OR $=0.529$, CI: $0.292-0.959)$.

\section{Outcomes and predictors of in-hospital mortality}

All patients received antibiotic therapy, with 160 (51.1\%) submitted to early surgery. Twenty-seven cases (8.6\%) were submitted to late surgical intervention based on their specific condition such as hemodynamic instability, uncontrolled sepsis, shock and organ failure (Table 5).
A total of 35 patients (11.2\%) died in hospital, 11 in the early-period group and 24 in the later-period group. Of these, 14 died from acute heart failure, 10 from cerebrovascular events, 9 from septic shock and multiple organ failure, and 1 each from severe arrhythmia and acute myelitis. There was no significant difference in in-hospital mortality between two groups.

Multivariate analysis of the clinical variables found to have statistical significance in the univariate analysis (Table 6) identified the following as independent predictors of in-hospital mortality: intravenous drug addicted $(\mathrm{OR}=4.290$, CI: 1.098-16.758), prosthetic valve endocarditis (OR $=7.374$, CI: 1.177-46.179), hemorrhagic stroke $(\mathrm{OR}=5.804, \mathrm{CI}: 1.830-18.413)$, acute congestive heart failure $(\mathrm{OR}=10.607, \mathrm{CI}: 3.842-29.284)$, renal insufficiency (OR $=9.268 \mathrm{CI}$ : 2.924-29.382), left-sided endocarditis ( $\mathrm{OR}=5.606, \mathrm{CI}: 1.461-21.512)$, and early surgery $(\mathrm{OR}=0.099$, CI:0.030-0.330) (Table 7). The goodness-

Table 4 Echocardiography results of 313 patients

\begin{tabular}{|c|c|c|c|c|c|c|c|}
\hline \multirow[t]{2}{*}{ Variable } & \multirow{2}{*}{$\begin{array}{l}\text { Total } \\
N=313\end{array}$} & \multirow{2}{*}{$\begin{array}{l}\text { Early-period Group } \\
\mathrm{N}=97\end{array}$} & \multirow{2}{*}{$\begin{array}{l}\text { Later-period Group } \\
\mathrm{N}=216\end{array}$} & \multirow[t]{2}{*}{ OR } & \multicolumn{2}{|l|}{$95 \% \mathrm{Cl}$} & \multirow[t]{2}{*}{$P$} \\
\hline & & & & & Lower & Upper & \\
\hline \multicolumn{8}{|l|}{ Vegetation } \\
\hline No vegetation & 39 (12.5) & $6(6.2)$ & $33(15.3)$ & 2.735 & 1.106 & 6.764 & 0.024 \\
\hline Left cardiac valve & 199 (63.6) & $60(61.9)$ & $139(64.4)$ & 1.113 & 0.678 & 1.827 & 0.671 \\
\hline Mitral valve & $105(33.5)$ & $30(30.9)$ & $75(34.7)$ & 1.188 & 0.711 & 1.986 & 0.511 \\
\hline Aortic valve & $72(23.0)$ & $23(23.7)$ & $49(22.7)$ & 0.944 & 0.536 & 1.663 & 0.842 \\
\hline Mitral and aortic valve & $22(7.0)$ & $7(7.2)$ & $15(6.9)$ & 0.959 & 0.378 & 2.434 & 0.931 \\
\hline Right cardiac valve & 60 (19.2) & $25(25.8)$ & $35(16.2)$ & 0.557 & 0.311 & 0.996 & 0.047 \\
\hline Tricuspid valve & $56(17.9)$ & $24(24.7)$ & $32(14.8)$ & 0.529 & 0.292 & 0.959 & 0.034 \\
\hline Pulmonary valve & $4(1.3)$ & $1(1.0)$ & $3(1.4)$ & 1.352 & 0.139 & 13.166 & 0.777 \\
\hline Both left and right cardiac valve & $9(2.9)$ & $2(2.1)$ & $7(3.2)$ & 1.591 & 0.324 & 7.802 & 0.833 \\
\hline Peripheral abscess & $14(4.5)$ & $5(5.2)$ & $9(4.2)$ & 0.800 & 0.261 & 2.453 & 0.924 \\
\hline Severe regurgitation & $190(60.7)$ & $57(58.8)$ & 133 (61.6) & 1.124 & 0.690 & 1.833 & 0.638 \\
\hline
\end{tabular}

Variables are presented as count (\%). $P$ value were estimated by Chi-squared tests 
Table 5 Treatment regimen and outcomes of 313 IE patients

\begin{tabular}{|c|c|c|c|c|c|c|c|}
\hline \multirow[t]{2}{*}{ Variable } & \multirow{2}{*}{$\begin{array}{l}\text { Total } \\
\mathrm{N}=313\end{array}$} & \multirow{2}{*}{$\begin{array}{l}\text { Early-period Group } \\
\mathrm{N}=97\end{array}$} & \multirow{2}{*}{$\begin{array}{l}\text { Later-period Group } \\
\mathrm{N}=216\end{array}$} & \multirow[t]{2}{*}{ OR } & \multicolumn{2}{|l|}{$95 \% \mathrm{Cl}$} & \multirow[t]{2}{*}{$P$} \\
\hline & & & & & lower & upper & \\
\hline \multicolumn{8}{|l|}{ Treatment regimen } \\
\hline Antibiotic plus surgery & $187(59.7)$ & $57(58.8)$ & $130(60.2)$ & 1.061 & 0.652 & 1.727 & 0.812 \\
\hline Early surgery & $160(51.1)$ & $48(49.5)$ & $112(51.9)$ & 1.099 & 0.681 & 1.775 & 0.698 \\
\hline Late surgery & $27(8.6)$ & $9(9.3)$ & $18(8.3)$ & 0.889 & 0.384 & 2.056 & 0.783 \\
\hline Death & $35(11.2)$ & $13(13.4)$ & $22(10.2)$ & 0.733 & 0.352 & 1.523 & 0.404 \\
\hline Acute heart failure & $14(4.5)$ & $4(4.1)$ & $10(4.6)$ & 1.129 & 0.345 & 3.692 & 0.924 \\
\hline Cerebrovascular events & $10(3.2)$ & $3(3.1)$ & $7(3.2)$ & 1.049 & 0.266 & 4.147 & 0.781 \\
\hline Septic shock and multiple organ failure & $9(2.9)$ & $5(5.2)$ & $4(1.9)$ & 0.347 & 0.091 & 1.322 & 0.211 \\
\hline Others & $2(0.6)$ & $1(1.0)$ & $1(0.5)$ & 0.447 & 0.028 & $7.213+$ & $0.524 \dagger$ \\
\hline
\end{tabular}

Variables are presented as count (\%). $P$ value were estimated by Chi-squared tests or †Fisher exact tests

of-fit of the multivariable model was determined by Hosmer-Lemeshow test (Chi-square $=1.562, P=0.955)$.

\section{Discussion}

IE is a fatal disease with diversity of clinical manifestations and risk factors, continuing to be associated with high mortality despite of novel diagnostic and therapeutic strategies [1]. The demographics, predisposing factors, clinical features, and microbiological spectrum of IE have evolved in recent decades. Relative studies remain scarce in China, and are usually of small sample. Our study was aimed to better understand the regional characteristics and the changing profile of IE over 18 years in our hospital, and to evaluate independent factors that influence the outcome of IE. To our knowledge, this is the largest study on IE performed in our region over 18 years.

\section{Clinical features}

Many studies detected an increase in cases of IVDUrelated IE, a trend that has been documented in Australia [15], America [16-18] and Sweden [19]. Conversely, in our study, the proportion of IVDU-related IE declined by half in later-period group as the Chinese government had been stepping up efforts to crack down drug cartels [20], which might play an important reason for the changing profile of IE for 18 years in our region. IE patients in developed countries [8, 21-24] were markedly older than developing regions [10, 24-26]. The mean age of IE patients in the International Collaboration on Endocarditis-Prospective Cohort Study (ICEPCS), the largest cohort study of IE worldwide, was 57.9 years old [6], far older than ours (42.3 years old). As the young are more likely to be exposed to drugs compared to the middle-age and the old [17, 27], the downward trend of intravenous drugs abusing may be responsible for upward tendency of onset age in the later-period group. It is generally known that IVDU-related IE is more likely to be Staphylococcus aureus-related, and usually more frequently occur on tricuspid valve [27, 28]. With the significantly lower proportion of IVDUs, Staphylococcus aureus cultured from blood and vegetations on tricuspid valve decreased strikingly in the laterperiod group. Meanwhile, the decrease of patients with pulmonary embolism in the later-period group could be explained by less numerous right-sided IE. Besides, the lower occurrence of renal insufficiency in the later-period group might benefit from the reduction in Staphylococcus aureus, which was perceived as a risk factors for acute renal failure in some study [29].

Beyond the IVDU-related IE, there were still some other points below worth mentioning.

IE patients of the later-period group developed less ischemic stroke. Previous studies reported that Staphylococcus aureus infection and vegetations on the mitral valve were risk factors for ischemic stroke [30, 31], but among the patients in this study, the later-period group showed a lower percentage of Staphylococcus aureus infection and a nonsignificant rise in patients with mitral vegetations. We speculate that an older age at onset and a higher proportion of diabetics may play a more important role in triggering ischemic stroke.

The ICE-PCS reported that $87.1 \%$ of cases had echocardiographic evidence of vegetation [6], similar to our data. The negative echocardiography results (absence of vegetations) is still a stumbling block to diagnosis, which increased significantly in the later-period group. The most frequent explanations for a negative echocardiogram are very small vegetations, non-oscillating and/or atypically located vegetations, or severe, preexisting lesions from rheumatic heart disease or degenerative heart disease in heart valves [32]. For suspected cases or cases with negative TTE, especially when a prosthetic heart valve or an intracardiac device is present, the appliance of TOE is strongly recommended $[11,32]$. However, we observed that TOE was rarely 
Table 6 Factors associated with in-hospital mortality: univariate analysis

\begin{tabular}{|c|c|c|c|c|c|c|c|}
\hline \multirow[t]{2}{*}{ Factor } & \multirow[t]{2}{*}{ Category } & \multirow[t]{2}{*}{ Number } & \multirow[t]{2}{*}{ Deaths } & \multirow[t]{2}{*}{ OR } & \multicolumn{2}{|c|}{$\underline{95 \% \mathrm{Cl}}$} & \multirow[t]{2}{*}{$P$} \\
\hline & & & & & lower & upper & \\
\hline \multicolumn{8}{|l|}{ Basic } \\
\hline \multirow[t]{2}{*}{ Age } & $<40$ & 149 & $11(7.38)$ & 0.465 & 0.219 & 0.986 & 0.042 \\
\hline & $>=40$ & 164 & $24(14.63)$ & & & & \\
\hline \multirow[t]{2}{*}{ Sex } & male & 226 & $32(14.16)$ & 4.619 & 1.376 & 15.501 & 0.007 \\
\hline & female & 87 & $3(3.45)$ & & & & \\
\hline \multirow[t]{2}{*}{ Health care-related } & yes & 21 & 7(33.33) & 4.714 & 1.756 & 12.654 & 0.003 \\
\hline & no & 292 & 28(9.59) & & & & \\
\hline \multirow[t]{2}{*}{ Intravenous drug users } & yes & 51 & $10(19.61)$ & 2.312 & 1.034 & 5.171 & 0.037 \\
\hline & no & 262 & $25(9.54)$ & & & & \\
\hline \multicolumn{8}{|l|}{ Clinical findings } \\
\hline \multirow[t]{2}{*}{ Hemorrhagic stroke } & yes & 27 & 10(37.04) & 6.141 & 2.541 & 14.840 & $<0.001$ \\
\hline & no & 286 & $25(8.74)$ & & & & \\
\hline \multirow[t]{2}{*}{ Embolism } & yes & 82 & 15(18.29) & 2.362 & 1.145 & 4.870 & 0.017 \\
\hline & no & 231 & $20(8.66)$ & & & & \\
\hline \multirow[t]{2}{*}{ Ischemic stroke } & yes & 69 & $14(20.29)$ & 2.703 & 1.292 & 5.653 & 0.007 \\
\hline & no & 244 & $21(8.61)$ & & & & \\
\hline \multirow[t]{2}{*}{ Heart insufficiency } & yes & 182 & $27(14.84)$ & 2.678 & 1.175 & 6.103 & 0.016 \\
\hline & no & 131 & $8(6.11)$ & & & & \\
\hline \multirow[t]{2}{*}{ Acute congestive heart failure } & yes & 67 & 21(31.34) & 7.565 & 3.586 & 15.961 & $<0.001$ \\
\hline & no & 246 & 14(5.69) & & & & \\
\hline \multirow[t]{2}{*}{ Renal insufficiency } & yes & 28 & $12(42.86)$ & 8.543 & 3.610 & 20.217 & $<0.001$ \\
\hline & no & 285 & 23(8.07) & & & & \\
\hline \multirow[t]{2}{*}{ Pneumonia } & yes & 145 & $25(17.24)$ & 3.292 & 1.523 & 7.115 & 0.002 \\
\hline & no & 168 & $10(5.95)$ & & & & \\
\hline \multirow[t]{2}{*}{ Pleural effusion } & yes & 135 & $21(15.56)$ & 2.158 & 1.053 & 4.421 & 0.033 \\
\hline & no & 178 & $14(7.87)$ & & & & \\
\hline \multirow[t]{2}{*}{ Albumin } & $<30 \mathrm{~g} / \mathrm{L}$ & 147 & $24(16.33)$ & 2.747 & 1.297 & 5.848 & 0.007 \\
\hline & $>30 \mathrm{~g} / \mathrm{L}$ & 166 & $11(6.63)$ & & & & \\
\hline \multicolumn{8}{|l|}{ Microorganism } \\
\hline Blood culture & Positive & 181 & $25(13.81)$ & 1.955 & 0.905 & 4.225 & 0.084 \\
\hline & Negative & 132 & 10(7.58) & & & & \\
\hline Staphylococcus aureus & yes & 46 & $9(19.57)$ & 2.255 & 0.980 & 5.188 & 0.051 \\
\hline & no & 267 & $26(9.74)$ & & & & \\
\hline Fungi & yes & 6 & $3(50.00)$ & 8.594 & 1.664 & 44.375 & 0.002 \\
\hline & no & 307 & $32(10.42)$ & & & & \\
\hline Echocardiography & & & & & & & \\
\hline Vegetaion & Negative & 39 & $0(0.00)$ & 1.146 & 1.096 & 1.200 & 0.036 \\
\hline & Positive & 181 & 35(19.34) & & & & \\
\hline Left heart & yes & 199 & $28(14.07)$ & 2.503 & 1.056 & 5.931 & 0.032 \\
\hline & no & 114 & $7(6.14)$ & & & & \\
\hline Both left and right heart & yes & 9 & $4(44.44)$ & 7.045 & 1.797 & 27.621 & 0.007 \\
\hline & no & 304 & $31(10.20)$ & & & & \\
\hline
\end{tabular}


Table 6 Factors associated with in-hospital mortality: univariate analysis (Continued)

\begin{tabular}{|c|c|c|c|c|c|c|c|}
\hline \multirow[t]{2}{*}{ Factor } & \multirow[t]{2}{*}{ Category } & \multirow[t]{2}{*}{ Number } & \multirow[t]{2}{*}{ Deaths } & \multirow[t]{2}{*}{ OR } & \multicolumn{2}{|c|}{$95 \% \mathrm{Cl}$} & \multirow[t]{2}{*}{ P } \\
\hline & & & & & lower & upper & \\
\hline \multirow[t]{2}{*}{ Valve type } & Prosthetic & 11 & 4(36.36) & 4.995 & 1.384 & 18.029 & 0.027 \\
\hline & Native & 302 & $31(10.26)$ & & & & \\
\hline \multirow[t]{2}{*}{ Surgery treatment } & yes & 187 & $9(4.81)$ & 0.194 & 0.088 & 0.431 & $<0.001$ \\
\hline & no & 126 & $26(20.63)$ & & & & \\
\hline \multirow[t]{2}{*}{ Early sugery } & yes & 160 & $6(3.75)$ & 0.167 & 0.067 & 0.414 & $<0.001$ \\
\hline & no & 153 & $29(18.95)$ & & & & \\
\hline
\end{tabular}

$P$ value were estimated by Chi-squared tests or +Fisher exact tests

applied to above cases in our study, which exactly need an improvement.

Up to $41.8 \%$ of patients were blood-culture negative in our study, which was similar to other region of China (from 31.4 to 51\%) [10, 26, 33]. According to the available literature, the incidence of $\mathrm{BCNE}$ has been reported to be 7\% in North America [6], 5.2-24\% in Europe [9, 24, 34, 35], 20\% in Japan [36], 20\% in South America [6], 31-69\% in South Asia [24, 37, 38]. Therefore we could draw a conclusion that BCNE occurs more frequently in developing countries. BCNE is associated with inappropriate antibiotic treatment, faulty culture techniques, atypical pathogens that are difficult to culture or identify [39]. Among these factors, the misuse and overuse of antibiotics remained a problem, especially for patients with long-term fever. Atypical pathogens can be identified by serological analysis and polymerase chain reaction (PCR) assays of blood and pathological specimens [40], which is difficult to realize in clinical practice due to economic and subjective factors. With the development of improved microbial culture techniques, increased medical expertise, and more accurate specifications for the diagnostic and treatment processes, the negative blood-culture rate achieved a remarkable decline in the later-period group. Still, there is room for improvement and research efforts need to be continued.

Table 7 Multivariate predictors of in-hospital mortality

\begin{tabular}{lllllll}
\hline Factor & B & OR & \multicolumn{2}{l}{$95 \% \mathrm{Cl}$} & $P$ \\
\cline { 5 - 6 } & & & lower & upper & \\
\hline Intravenous drug users & 1.456 & 4.290 & 1.098 & 16.758 & 0.036 \\
Prosthetic valve endocarditis & 1.998 & 7.374 & 1.177 & 46.179 & 0.033 \\
Hemorrhagic stroke & 1.759 & 5.804 & 1.830 & 18.413 & 0.003 \\
Acute congestive heart failure & 2.362 & 10.607 & 3.842 & 29.284 & $<0.001$ \\
Renal insufficiency & 2.227 & 9.268 & 2.924 & 29.382 & $<0.001$ \\
Left-sided endocarditis & 1.724 & 5.606 & 1.461 & 21.512 & 0.012 \\
Early surgery & -2.311 & 0.099 & 0.030 & 0.330 & $<0.001$ \\
Constant & -13.894 & & & & $<0.001$ \\
\hline
\end{tabular}

The goodness-of-fit of the multivariable model was determined by HosmerLemeshow test (Chi-square $=1.562, P=0.955$ )
A systematic review of 21 regional literatures in the world revealed that the average fatality rate of IE is $21.1 \% \pm 10.4 \%$ [2], and the ICE-PCS pointed out the inhospital mortality was $18 \%$ worldwide by average [6]. The in-hospital mortality of our study was $11.2 \%$, nearly approaching to the lower limit and quite similar to another research conducted in East China (10.9\%). Moreover, it is noteworthy that even with the novel diagnostic and therapeutic strategies available now, the in-hospital mortality did not strikingly differ between the two groups, which means minimizing the in-hospital mortality of IE is still a long-term undertaking.

\section{Risk factors for in-hospital mortality}

To explore the independent risk factors for in-hospital mortality, we performed a forward stepwise logistic regression analysis model. The results indicated that IVDUs, prosthetic valve endocarditis $[6,41]$, hemorrhagic stroke, acute congestive heart failure [26, 42-44], renal insufficiency [42], left-sided endocarditis and early surgical treatment $[6,44-46]$ were the independent determinants of inhospital mortality. Among these factors, prosthetic valve endocarditis had the highest odds ratio. Many of them are also confirmed by previous researches. Some factors, such as age, embolism (or Ischemic stroke), health-related endocarditis. Were finally ruled out from forward stepwise method logistic regression analysis model, probably due to the multicollinearity with other variables. In other studies, increasing age, health care-associated IE, Staphylococcus aureus related IE, coagulase-negative staphylococcal infection, paravalvular complications and diabetes mellitus $[6,8,47,48]$ are also important factors contributing to the in-hospital mortality. These discrepancies may due to differences in samples and study design.

Early surgery has been proved to be associated with a significantly lower in-hospital mortality rate as compared to medical therapy $[49,50]$ Mortality of patients who underwent surgery was one sixth of that of patients who did not have the surgery. In our study, up to $59.7 \%$ of our patients underwent surgery during hospitalization, which is similar to other regions like Brazil (52.4-55.0\%) [43], Spain (57.0\%) and France (31.0-71.0\%) [34], but 
relatively higher compared to Japan (17.0\%) [8] and North America (45.0\%). The ICE-PCSS showed that 46\% of patients worldwide underwent early surgery [46]. In our studies, nearly $51.1 \%$ of cases were admitted to early surgery, which turned to be the only protective factor for prognosis of IE in our multivariate model. We believe that good standard of care in our hospital, and relatively younger age were a major reason for patients to make aggressive decision of surgical treatment.

The difference of in-hospital mortality between IVDUrelated IE and none-IVDU-related IE was reported to be of no significance in previous studies $[18,51,52]$, inconsistent with our conclusion. We speculated that the higher Staphylococcus aureus septicemia and repeated infection brought by intravenous drugs busing might contribute to the higher in-hospital mortality. We strongly proposed to conduct more further studies so as to verify our conclusions.

\section{Limitation}

This study focused on a single-center in a general teaching hospital without long-term follow-up. Most patients came from south China, thus findings in this study may not be applicable to all populations. Besides, referral bias should be taken into consideration when describing the clinical spectrum and outcome of IE, as patients with more complications such as stroke, heart failure and new valvular regurgitation and surgery indications, who are more likely to be gravely ill patients, are more likely to choose a tertiary hospital [53]. So our conclusions may not apply to small hospital. However, our observations reflected a dynamic change of IE in our center over a period of eighteen consecutive years with a relatively large sample size, while relative study remains scarce in China. The geographic variations observed in our study will be of important value to profile the clinical feature of China and offer the reference for clinical decisions in our region.

\section{Conclusion}

In conclusion, intravenous drug abuse was less common in later-period group, which might result in a series of changes like older age of onset, fewer pulmonary embolism, renal failure, Staphylococcus aureus endocarditis and right-sided IE. More ischemic stroke was observed possibly due to older age. Also, patience in later-period showed more splenomegaly, lower BCNE rate and negative echocardiography results. The in-hospital mortality stayed still despite of the changing profile of IE. The multivariate analysis underlined the significance of prosthetic valve endocarditis, intravenous drug addicted, hemorrhagic stroke, congestive heart failure, renal insufficiency, left-sided endocarditis, fungal endocarditis and surgical treatment to in-hospital mortality.

\section{Abbreviations}

BC: Blood culture; Cl: Confidence interval; CT: Computed Tomography; ESC: European Society of Cardiology.; FDG: Fluorodeoxyglucose; IE: Infective endocarditis; IVDU: Intravenous drug users; NCBC: Blood culture-negative infective endocarditis; OR: Odds ratio; PCR: Polymerase chain reaction; TTE: Transthoracic echocardiography

\section{Authors' contributions}

Study conception and design: JP and ZNR. Acquisition, analysis and/or interpretation of data: ZNR. Drafting/revision of the work for intellectual content and context: JP, ZNR, XCM and HJC. Final approval and overall responsibility for the published work: JP. All of the authors read and approved the final manuscript.

\section{Funding}

Not applicable.

\section{Availability of data and materials}

The datasets used and/or analyzed during the current study are available from the corresponding author on reasonable request.

\section{Ethics approval and consent to participate}

The study was approved by the clinical research ethics committee of Nanfang Hospital of Southern Medical University. This was a retrospective study that did not need informed consent.

Consent for publication

Not applicable.

\section{Competing interests}

The authors declare no competing interests.

Received: 17 June 2019 Accepted: 31 October 2019

Published online: 08 November 2019

References

1. Cahill TJ, Prendergast BD. Infective endocarditis. Lancet. 2016; 387(10021):882

2. Abdulhak AAB, Baddour LM, Erwin PJ, Hoen B, Chu VH, Mensah GA, et al. Global and Regional Burden of Infective Endocarditis, 1990-2010 : Syst Rev Lit. Glob Heart 2014:9(1):131-143.

3. Yew HS, Murdoch DR. Global trends in infective endocarditis epidemiology. Curr Infect Dis Rep. 2012;14(4):367-72

4. Fowler VG, Miro JM, Bruno H, Cabell CH, Elias A, Ethan $\mathrm{R}$, et al. Staphylococcus aureus endocarditis: a consequence of medical progress. Jama. 2005;293(24):3012-21.

5. Seltonsuty C, Célard M, Moing VL, Docolecompte T, Chirouze C, lung B, et al. Preeminence of Staphylococcus aureus in infective endocarditis: a 1 year population-based survey. Clin Infect Dis. 2012;54(9):1230.

6. Murdoch DR, Corey GR, Hoen B, Miró JM, Fowler VG Jr, Bayer AS, et al. Clinical presentation, etiology, and outcome of infective endocarditis in the 21 st century: the international collaboration on endocarditis-prospective cohort study. JAMA Intern Med. 2009;169(5):463-73.

7. Nunes MCP, Gelape CL, Ferrari TCA. Profile of infective endocarditis at a tertiary care center in Brazil during a seven-year period: prognostic factors and in-hospital outcome. Int J Infect Dis. 2010;14(5):e394-e8.

8. Hase R, Otsuka Y, Yoshida K, Hosokawa N. Profile of infective endocarditis at a tertiary-care hospital in Japan over a 14-year period: characteristics, outcome and predictors for in-hospital mortality. Int J Infect Dis. 2015;33:62-6.

9. Ferrera C, Vilacosta I, Fernandez C, Lopez J, Olmos C, Sarria C, et al. Reassessment of blood culture-negative endocarditis: its profile is similar to that of blood culture-positive endocarditis. Rev Esp Cardiol (Engl Ed). 2012; 65(10):891-900.

10. $\mathrm{Xu} \mathrm{H}$, Cai $\mathrm{S}$, Dai $\mathrm{H}$. Characteristics of infective endocarditis in a tertiary Hospital in East China. PLoS One. 2016;11(11):e0166764

11. Gilbert H, Patrizio L, Antunes MJ, Maria Grazia B, Jean-Paul C, Francesco DZ, et al. 2015 ESC Guidelines for the management of infective endocarditis: The Task Force for the Management of Infective Endocarditis of the European Society of Cardiology (ESC) Endorsed by: European Association 
for Cardio-Thoracic Surgery (EACTS), the European Association of Nuclear Medicine (EANM). Eur Heart J. 2015;36(44):3075-128.

12. Bashore T, Ryan T, Li JS, Sexton DJ, Corey GR, Fowler VG Jr, et al. Proposed modifications to the Duke criteria for the diagnosis of infective endocarditis. Clin Infect Dis. 2000;30(4):633-8.

13. Benami R, Giladi M, Carmeli Y, Orniwasserlauf R, Siegmanigra Y. Hospitalacquired infective endocarditis: should the definition be broadened? Clin Infect Dis. 2004;38(6):843-50.

14. Narayanan MA, Haddad TM, Kalil AC, Kanmanthareddy A, Suri RM, Mansour $G$, et al. Early versus late surgical intervention or medical management for infective endocarditis: a systematic review and meta-analysis. Heart. 2016; 102(12):950-7.

15. Tung MK, Light M, Giri R, Lane S, Appelbe A, Harvey C, et al. Evolving epidemiology of injecting drug use-associated infective endocarditis: a regional Centre experience. Drug Alcohol Rev. 2015;34(4):412-7.

16. Cooper HL, Brady JE, Ciccarone D, Tempalski B, Gostnell K, Friedman SR, Nationwide increase in the number of hospitalizations for illicit injection drug use-related infective endocarditis. Clin Infect Dis. 2007;45(9):1200-3.

17. Wurcel AG, Anderson JE, KKH C, Skinner S, Knox TA, Snydman DR, et al. Increasing Infectious Endocarditis Admissions Among Young People Who Inject Drugs. Open Forum Infect Dis. 2016;3(3):ofw157.

18. Gray ME, Mcquade ETR, Scheld WM, Dillingham RA. Rising rates of injection drug use associated infective endocarditis in Virginia with missed opportunities for addiction treatment referral: a retrospective cohort study. BMC Infect Dis. 2018;18(1):532.

19. Asgeirsson $\mathrm{H}$, Thalme A, Weiland O. Low mortality but increasing incidence of Staphylococcus aureus endocarditis in people who inject drugs: experience from a Swedish referral hospital. Medicine. 2016;95(49):e5617.

20. Jia Z, Liu Z, Chu P, Mcgoogan JM, Cong M, Shi J, et al. Tracking the evolution of drug abuse in China, 2003-10: a retrospective, self-controlled study. Addiction. 2015;110(S1):4-10.

21. Murdoch DR, G Ralph C, Bruno H, Miró JM, Fowler VG, Bayer AS, et al. Clinical presentation, etiology, and outcome of infective endocarditis in the 21st century: the international collaboration on endocarditis-prospective cohort study. Arch Intern Med 2009;169(5):463-73.

22. Slipczuk L, Codolosa JN, Davila CD, Romero-Corral A, Yun J, Pressman GS, et al. Infective endocarditis epidemiology over five decades: a systematic review. PLoS One. 2013;8(12):e82665.

23. Sa DDCD, Tleyjeh IM, Anavekar NS, Schultz JC, Thomas JM, Lahr BD, et al. Epidemiological trends of infective endocarditis: a population-based study in Olmsted County. Minnesota Mayo Clin Proc. 2010;85(5):422-6.

24. George W, Adele L, Orathai P, Baggett HC, Didier R, Pierre-Edouard F, et al. Prospective comparison of infective endocarditis in Khon Kaen, Thailand and Rennes, France. Am J Trop Med Hyg. 2015;92(4):871-4.

25. Math RS, Gautam S, Shyam Sunder K, Mani K, Anita S, Arkalgud Sampath K et al. Prospective study of infective endocarditis from a developing country. Am Heart J. 2011;162(4):633-8.

26. Zhu W, Zhang Q, Zhang J. The changing epidemiology and clinical features of infective endocarditis: a retrospective study of 196 episodes in a teaching hospital in China. BMC Cardiovasc Disord. 2017;17(1):113.

27. Chahoud J, Yakan AS, Saad H, Kanj SS. Right-sided infective endocarditis and pulmonary infiltrates: an update. Cardiol Rev. 2016;24(5):1.

28. Sousa C, Botelho C, Rodrigues D, Azeredo J, Oliveira R. Infective endocarditis in intravenous drug abusers: an update. Eur J Clin Microbiol Infect Dis. 2012; 31(11):2905

29. Jiad E, Gill SK, Krutikov M, Turner D, Parkinson MH, Curtis C, et al. When the heart rules the head: ischaemic stroke and intracerebral haemorrhage complicating infective endocarditis. Pract Neurol. 2017;17(1):28-34.

30. Rizzi M, Ravasio V, Carobbio A, Mattucci I, Crapis M, Stellini R, et al. Predicting the occurrence of embolic events: an analysis of 1456 episodes of infective endocarditis from the Italian study on endocarditis (SEI). BMC Infect Dis. 2014;14(1):230.

31. Valenzuela I, Hunter MD, Sundheim K, Klein B, Dunn L, Sorabella R, et al. Clinical risk factors for acute ischemic and hemorrhagic stroke in patients with infective endocarditis. Intern Med J. 2018;48(9):1072-80.

32. Habib G, Badano L, Tribouilloy C, Vilacosta I, Zamorano JL, Galderisi M, et al. Recommendations for the practice of echocardiography in infective endocarditis. Eur J Echocardiogr. 2010;11(2):202.

33. Li L, Hongyue W, Linlin W, Jielin P, Hong Z. Changing profile of infective endocarditis: a clinicopathologic study of 220 patients in a single medical center from 1998 through 2009. Tex Heart Inst J. 2014;41(5):491-8.
34. Selton-Suty C, Celard M, Le Moing V, Doco-Lecompte T, Chirouze C, lung B, et al. Preeminence of Staphylococcus aureus in infective endocarditis: a 1year population-based survey. Clin Infect Dis. 2012;54(9):1230-9.

35. Maria W, Rune A, Lars O, Harriet H. A 10-year survey of blood culture negative endocarditis in Sweden: aminoglycoside therapy is important for survival. Scand J Infect Dis. 2008;40(4):279.

36. Satoshi N, Kotaro M, Takahiro O, Yoshihiro K, Haruko Y, Sotaro H. Recent picture of infective endocarditis in Japan--lessons from cardiac disease registration (CADRE-IE). Circ J. 2013;77(6):1558-64.

37. Naveen G, Bhuwanesh K, Nitish G, Satendra T, Aditya K, Praveen G, et al. Characteristics of infective endocarditis in a developing country-clinical profile and outcome in 192 Indian patients, 1992-2001. Int J Cardiol. 2005; 98(2):253-60.

38. Mirabel M, Rattanavong $S$, Frichitthavong $K$, Chu V, Kesone $P$, Thongsith $P$, et al. Infective endocarditis in the Lao PDR: clinical characteristics and outcomes in a developing country. Int J Cardiol. 2015;180:270-3.

39. Pierre H, Didier R. Blood culture-negative endocarditis in a reference center: etiologic diagnosis of 348 cases. Medicine. 2005;84(3):162-73.

40. Fournier PE, Thuny FH, Lepidi H, Casalta JP, Arzouni JP, Maurin M, et al. Comprehensive diagnostic strategy for blood culture-negative endocarditis: a prospective study of 819 new cases. Clin Infect Dis. 2010;51(2):131-40.

41. Tran HM, Truong VT, Tmn N, Qpv B, Nguyen HC, Le T, et al. Microbiological profile and risk factors for in-hospital mortality of infective endocarditis in tertiary care hospitals of South Vietnam. PLoS One. 2017;12(12):e0189421.

42. Nakagawa T, Wada H, Sakakura K, Yamada Y, Ishida K, Ibe T, et al. Clinical features of infective endocarditis: comparison between the 1990s and 2000s - journal of cardiology. J Cardiol. 2014;63(2):145-8.

43. Nunes MCP, Coelho RMP, Barros TLS, Madureira DA, Reis RCP, Costa PHN, et al. Outcome of infective endocarditis in the current era: early predictors of poor prognosis. Int J Infect Dis. 2018;68:102-7.

44. Todd K, Lawrence P, Christophe T, Claudia C, Roberta C, Vivian C, et al. Association between valvular surgery and mortality among patients with infective endocarditis complicated by heart failure. Jama the Journal of the American Medical Association. 2011;306(20):2239-47.

45. Aksoy O, Sexton DJ, Wang A, Pappas PA, Kourany W, Chu V, et al. Early surgery in patients with infective endocarditis: a propensity score analysis. Clin Infect Dis. 2007:44(3):364-72.

46. Lalani T, Cabell CH, Benjamin DK, Lasca O, Naber C, Fowler VG Jr, et al. Analysis of the impact of early surgery on in-hospital mortality of native valve endocarditis: use of propensity score and instrumental variable methods to adjust for treatment-selection bias. Circulation. 2010;121(8): 1005-13.

47. Emanuele DM, Suzanne B, Christine SS. Marie-Fran?Oise T, Bruno B, Emilio B, et al. current features of infective endocarditis in elderly patients: results of the international collaboration on endocarditis prospective cohort study. Arch Intern Med. 2008;168(19):2095-103.

48. Kourany WM, Miro JM, Moreno A, Corey GR, Pappas PA, Abrutyn E, et al. Influence of diabetes mellitus on the clinical manifestations and prognosis of infective endocarditis: a report from the international collaboration on endocarditis-merged database. Scand J Infect Dis. 2006;38(8):613.

49. Liang F, Song B, Liu R, Yang L, Tang H, Li Y. Optimal timing for early surgery in infective endocarditis: a meta-analysis. Interact Cardiovasc Thorac Surg. 2016;22(3):336-45

50. Duk-Hyun K, Yong-Jin K, Sung-Han K, Byung Joo S, Dae-Hee K, Sung-Cheol $Y$, et al. Early surgery versus conventional treatment for infective endocarditis. N Engl J Med. 2012;366(26):2466.

51. Leahey PA, Lasalvia MT, Rosenthal ES, Karchmer AW, Rowley CF. High morbidity and mortality among patients with sentinel admission for injection drug use-related infective endocarditis. Open Forum Infect Dis. 2019;6(4):ofz089

52. Hartman L, Barnes E, Bachmann L, Schafer K, Lovato J, Files DC. Opiate injection-associated infective endocarditis in the southeastern United States. Am J Med Sci. 2016;352(6):603.

53. Kanafani ZA, Kanj SS, Cabell CH, Cecchi E, Ramos ADO, Lejko-Zupanc T, et al. Revisiting the effect of referral bias on the clinical spectrum of infective endocarditis in adults. Eur J Clin Microbiol Infect Dis. 2010;29(10):1203-10.

\section{Publisher's Note}

Springer Nature remains neutral with regard to jurisdictional claims in published maps and institutional affiliations. 